OLIVEIRA, A.F.M. et al. O processo de domesticação no comportamento dos animais de produção. PUBVET, Londrina, V. 5, N. 31, Ed. 178, Art. 1204, 2011.

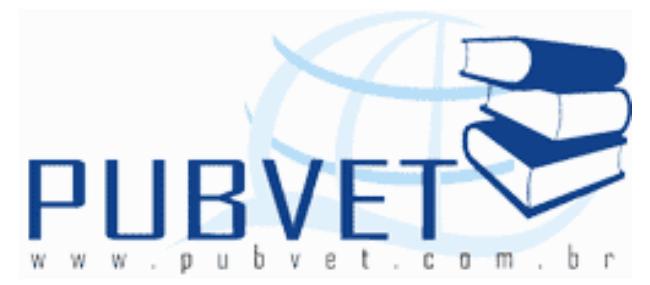

PUBVET, Publicações em Medicina Veterinária e Zootecnia.

\title{
O processo de domesticação no comportamento dos animais de produção
}

Aparecida de Fátima Madella-Oliveira ${ }^{1}$, Célia Raquel Quirino ${ }^{2}$, Carlos Ramon Ruiz-Miranda ${ }^{3}$, Francisco Aloizio Fonseca ${ }^{2}$

${ }^{1}$ Professora do Instituto Federal do Espírito Santo- Campus de Alegre, ES

2 Professora do Laboratório de Reprodução e Melhoramento Genético Animal do Centro Ciências e Tecnologias Agropecuárias, Universidade Estadual do Norte Fluminense Campos dos Goytacazes, RJ

${ }^{3}$ Professor do Laboratório de Ciências Ambientais do Centro de Biociências e Biotecnologia, Universidade Estadual do Norte Fluminense, RJ

\section{Resumo}

Esta revisão apresenta informações sobre o efeito da domesticação no comportamento dos animais de produção. Tem por objetivo comparar as algumas definições de domesticação, descrever os fatores que a influenciaram e descrever o comportamento reprodutivo, materno, alimentar e social.

Palavras-chave: Domesticação, socialização.

\section{The process of domestication on the behavior of farm animals}

\section{Abstract}

This review provides information on the effect of domestication on the behavior of farm animals. The objective was to compare the domestication of some 
OLIVEIRA, A.F.M. et al. O processo de domesticação no comportamento dos animais de produção. PUBVET, Londrina, V. 5, N. 31, Ed. 178, Art. 1204, 2011.

definitions, describe the factors that influenced and describe the reproductive, maternal, food and social behavior.

Keywords: Domestication, socialization.

\section{Introdução}

A domesticação é uma das maiores realizações da humanidade (Murphey e Ruiz-Miranda, 1998). No contexto histórico da domesticação, as reações emocionais dos animais em relação ao homem, como a tendência de fuga ou da agressão, provavelmente desempenharam importante papel na definição da espécie escolhida para ser domesticada.

As ovelhas e as cabras foram os primeiros animais de produção a serem domesticados e ocorreu principalmente no Oriente Médio e na Ásia (Fig. 1), aproximadamente 10.000 anos atrás, a domesticação de bovinos começou aproximadamente entre 8.000 a 10.000 anos atrás e foi consequência de procura de alimento protéico por parte do homem (Simm et al., 1996).

A domesticação dos suínos começou no Sudoeste da Ásia (China) aproximadamente 9.000 anos atrás (Fig.2). O burro foi domesticado depois, ao redor de 6.000 anos no Noroeste da África (Bruford et al., 2003). O cavalo foi domesticado no Centro da Ásia (Fig.3) há 5.000 anos e os búfalos foram domesticados há 4.000 anos no Sudeste da Ásia (China). 
OLIVEIRA, A.F.M. et al. O processo de domesticação no comportamento dos animais de produção. PUBVET, Londrina, V. 5, N. 31, Ed. 178, Art. 1204, 2011.

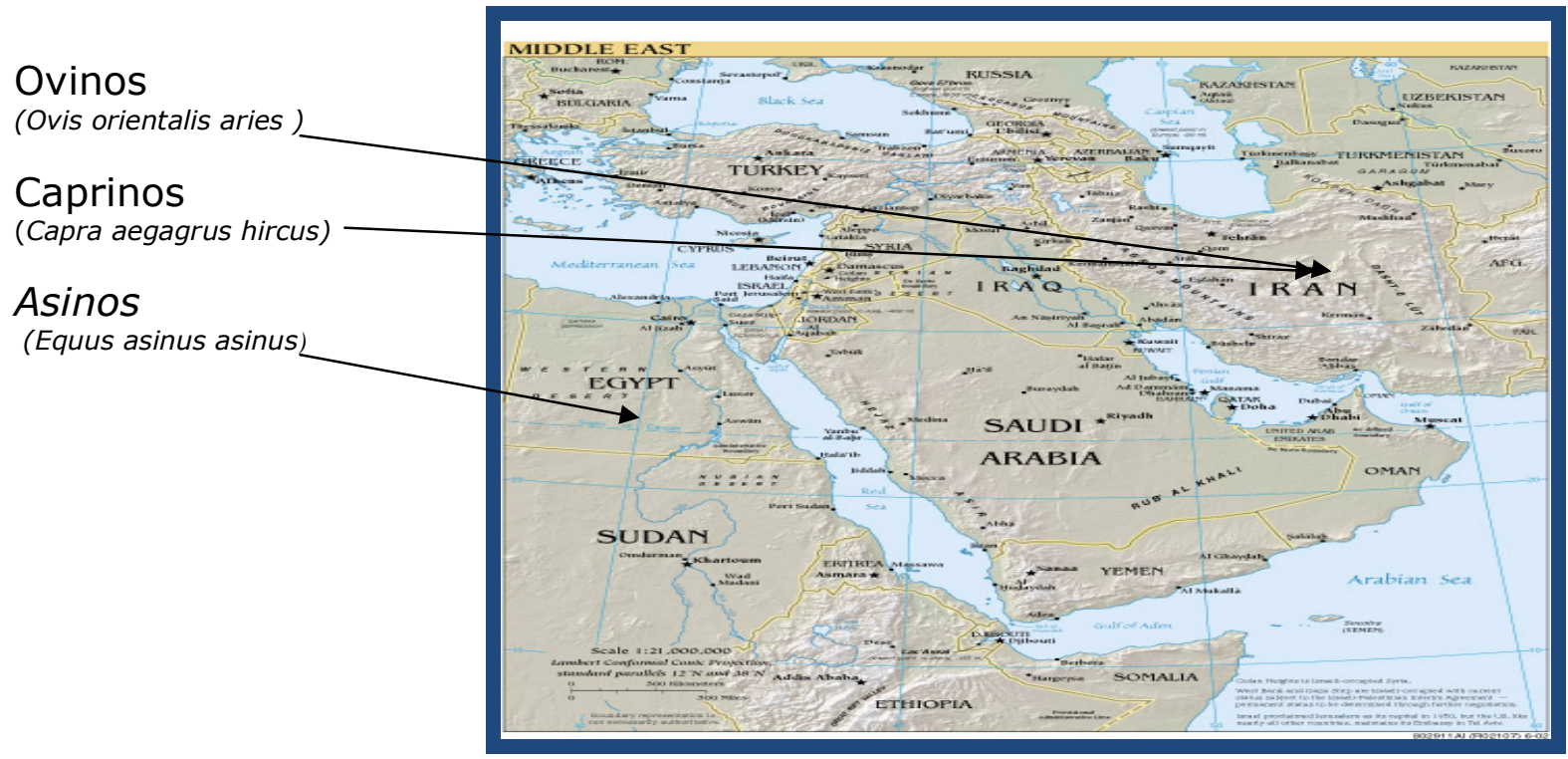

Figura 1- As espécies domesticadas no Oeste da Ásia.

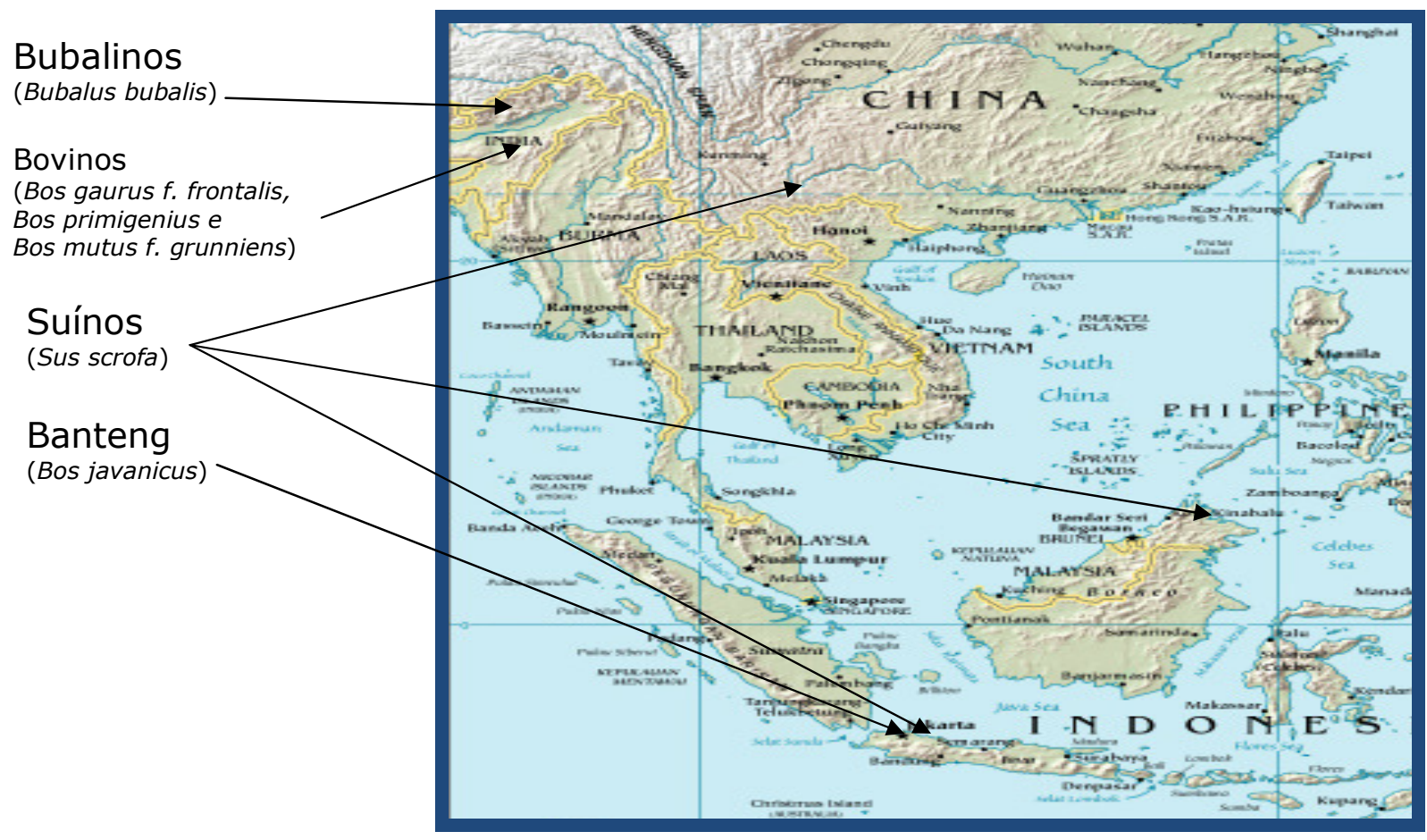

Figura 2 - Espécies domesticadas no Sudoeste da Ásia 
OLIVEIRA, A.F.M. et al. O processo de domesticação no comportamento dos animais de produção. PUBVET, Londrina, V. 5, N. 31, Ed. 178, Art. 1204, 2011.

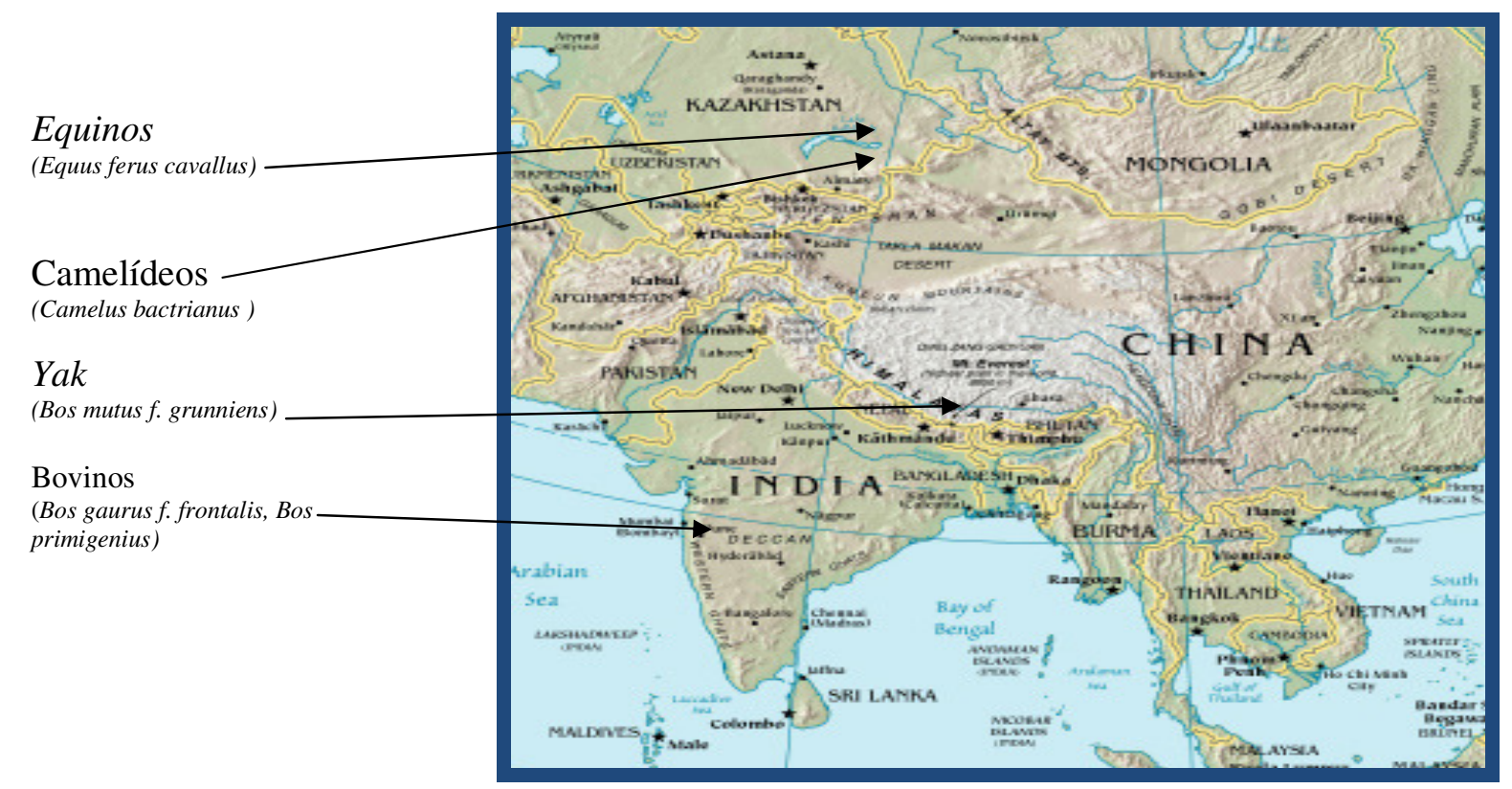

Figura 3 - Espécies domesticadas no Centro e Sul da Ásia.

Mas, recentemente, há 3.000 anos, foram domesticados o camelo na Ásia Central e Ihama, alpaca e vincunha na América da Sul.

Há pequenas evidencias de que a domesticação resultou em perda de comportamento do repertório das espécies, assim, adicionando novos comportamentos a estes animais de produção (Fig. 4). O que é muito importante, pois indica que as espécies domésticas são capazes de se comportar de um modo semelhante às selvagens. Andersen et al. (2006) comentaram que não deve-se esperar que sejam necessariamente idênticos os efeitos do processo de domesticação nas diversas espécies domesticadas.

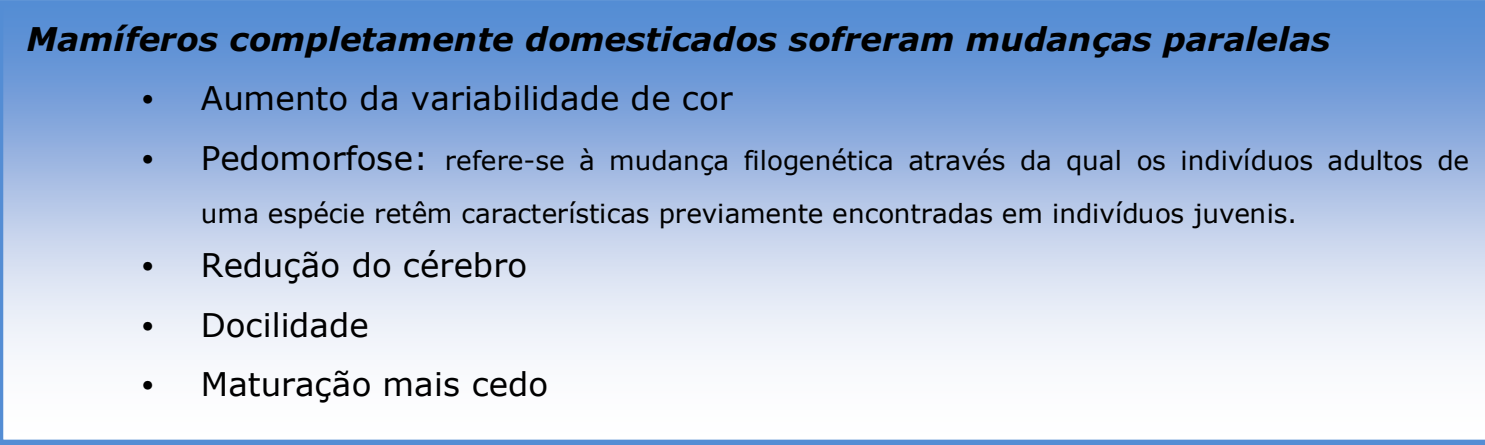

Figura 4 - Mudanças de comportamento devido à domesticação. 
OLIVEIRA, A.F.M. et al. O processo de domesticação no comportamento dos animais de produção. PUBVET, Londrina, V. 5, N. 31, Ed. 178, Art. 1204, 2011.

Essa revisão teve como objetivo avaliar o efeito da domesticação no comportamento dos animais de produção, focalizando as modificações nos comportamentos: reprodutivo, materno, alimentar e social.

\section{Definição domesticação}

Diversas definições para domesticação podem ser encontradas na literatura. Doméstico tem sua origem do latim "domus" significa casa. Os animais domésticos são os que estão sob o domínio do homem, não individualmente, através das gerações.

Como foi sugerido por Darwin em 1868 (citado por Price, 1999) a domesticação é mais do que amansar os animais, podendo ocorrer sem consenso e esforço por parte do homem. Pode-se citar que a domesticação dos animais em cativeiro pode aumentar a fecundidade e levar a modificações como atrofia de certos órgãos.

Price (1984) definiu domesticação como um processo de adaptação de uma população selvagem às condições de cativeiro, combinado com um processo de mudanças genéticas ao longo das gerações.

Segundo Hemmer (1990), domesticação pode-se referir ao convívio de um animal em casa sob o domínio do homem ou criado e reproduzido em cativeiro e de mansidão natural para uma utilidade ou serviço.

Segundo Murphey e Ruiz-Miranda (1998) a domesticação é o resultado de um mutualismo, uma dependência recíproca entre os humanos e espécies domesticadas.

Price (1999) relatou que a definição de domesticação citada por ele em 1984 foi bastante simplificada e que não assume que os genes e o ambiente operam como fatores independentes que aditivamente combinam-se para determinar resultados no fenótipo.

Gillespie (2002) define que a domesticação é adaptar o comportamento do animal para ajustá-lo às necessidades do homem. 
OLIVEIRA, A.F.M. et al. O processo de domesticação no comportamento dos animais de produção. PUBVET, Londrina, V. 5, N. 31, Ed. 178, Art. 1204, 2011.

Há um consenso que a domesticação é um processo que inclui contínua associação entre o homem e os animais (Haber e Dayan, 2004). Assim, observa-se uma dificuldade em formular uma definição para domesticação pelos muitos fatores que contribuem para o processo de domesticação, podendo ser significativos em termos evolutivos e biológicos.

Na Figura 5 apresenta-se um resumo dos atributos que são necessários para a domesticação dos animais.

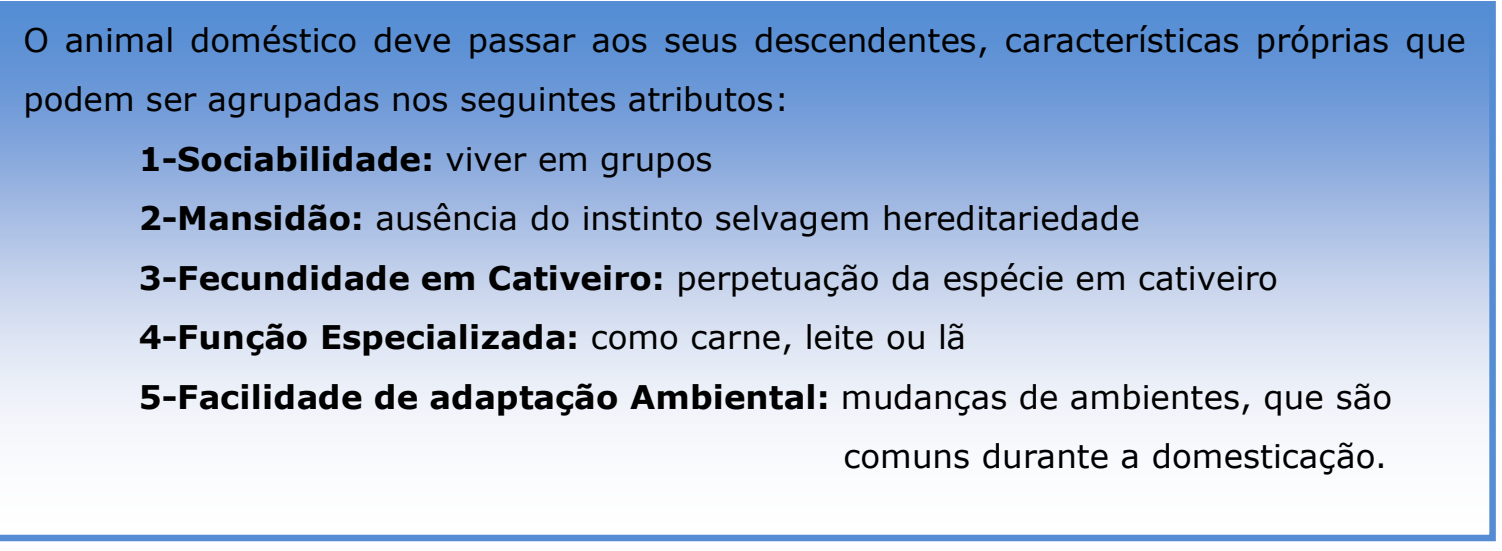

Figura 5 - Atributos dos animais domésticos.

\section{Fatores que influenciaram na domesticação}

Segundo Fox (1968) os principais fatores que influenciaram diretamente no comportamento e nos mecanismos inatos do processo de domesticação foram: (1) Trocar o ambiente natural por um artificial ou similar ao natural, exemplo às condições em cativeiro; (2) Seleção genética: a - docilidade, o manejo também influencia na escolha da espécie que poderá ser domesticada. As bases do temperamento e comportamento são herdadas e controladas por genes; b- seleção por adaptabilidade e/ou adaptação a diferentes ambientes domésticos, diferenças regionais, climáticas e nutricionais; c - seleção para aumentar as características econômicas desejáveis - alta fertilidade, rápido crescimento, eficiência em conversão alimentar e alta produção de leite; d - 
OLIVEIRA, A.F.M. et al. O processo de domesticação no comportamento dos animais de produção. PUBVET, Londrina, V. 5, N. 31, Ed. 178, Art. 1204, 2011.

seleção para prolongar o estado infantil; e- redução seletiva das características selvagens através de seleção dos neonatos; e f - cruzamento seletivo entre as raças mais produtivas e as raças mais adaptadas.

Segundo Price (1984 e 1999) os mecanismos seletivos atuantes nesse processo de domesticação seriam: (1) a seleção artificial exercida intencionalmente ou não pelo domesticador (por exemplo, a escolha para reprodução dos animais mais dóceis); (2) a diminuição da pressão seletiva que atua no ambiente natural (ainda que diminuída, esta pressão pode atuar em determinados comportamentos, como o comportamento reprodutivo); (3) os endocruzamentos e a restrição de trocas gênicas entre populações que favorecem uma ou poucas características, diminuindo a variabilidade gênica da população.

Os efeitos da domesticação têm sido avaliados através de comparação em estudos transversais e longitudinais de espécies domesticadas e selvagens em condições padronizadas. As diferenças encontradas podem ser de caráter: (1) morfológico, como as mudanças no tamanho do corpo e no padrão de crescimento e internamente na diminuição do intestino (Diamond, 2002; Haber e Dayan, 2004) (2) comportamental, como a sensação de medo reduzida e a sociabilidade aumentada (Price, 1999) e (3) fisiológica, como as respostas endócrinas no ciclo reprodutivo e maturidade sexual precoce (Setchell, 1992; Jensen, 2006).

Em relação à morfologia, com o relaxamento da seleção natural e dos predadores na maioria das espécies domésticas, a cabeça e o tamanho do cérebro diminuíram e os órgãos do sentido ficaram menos aguçados do que nos animais selvagens. Cérebro desenvolvido e olhos com visão aguçada são essenciais à sobrevivência dos animais selvagens, mas para os animais domésticos representa um desperdício importante de energia (Diamond, 2002). Foram observadas em bovinos uma redução contínua no tamanho do corpo, embora sem mudança na forma do corpo (Haber e Dayan, 2004). 
OLIVEIRA, A.F.M. et al. O processo de domesticação no comportamento dos animais de produção. PUBVET, Londrina, V. 5, N. 31, Ed. 178, Art. 1204, 2011.

Nos aspectos fisiológicos em relação ao processo de domesticação, Setchell, (1992) relata mudanças nas respostas endócrinas e no ciclo estral dos animais de produção como bovinos, ovinos e suínos.

Com respeito ao comportamento, pode ser discutido que a domesticação resultou principalmente dentro do aspecto quantitativo em lugar de mudanças qualitativas. Características do comportamento não aparecem e desaparecem, mas sim, as mudanças das expressões dos limiares (Price, 1999).

Na Figura 6 apresenta um resumo dos fatores, mecanismos e efeitos da domesticação

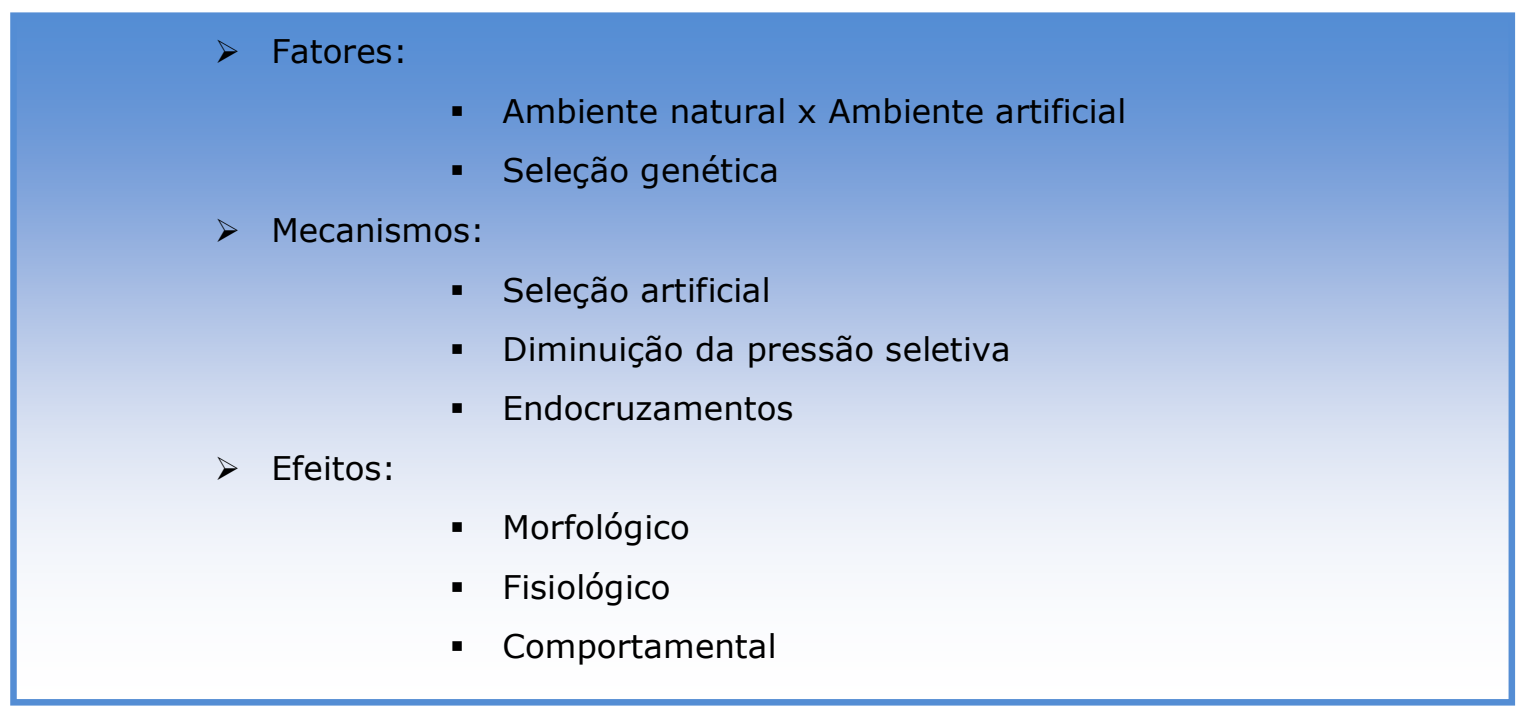

Figura 6 - Fatores, mecanismos e efeitos da domesticação.

\section{Comportamento reprodutivo na domesticação}

Em muitos aspectos, os animais domésticos diferem muito do seu comportamento dos animais selvagens. Alguns pesquisadores após trabalhar com animais selvagens observaram que os animais domésticos apresentaram uma degeneração, ou seja, perderam os rituais do comportamento sexual dos animais selvagens e ficaram mais juvenis (Beilharz, 1985). 
OLIVEIRA, A.F.M. et al. O processo de domesticação no comportamento dos animais de produção. PUBVET, Londrina, V. 5, N. 31, Ed. 178, Art. 1204, 2011.

Os padrões comportamentais estão associados à corte e à cópula, ao nascimento, ao cuidado materno e às tentativas de amamentação do filhote recém-nascido. Estes padrões de comportamento têm sido abandonados pela domesticação e restringidos ou modificados pelas condições impostas de acordo com as necessidades do manejo zootécnico. Tais manejos incluem o confinamento em piquetes, currais ou baias; a segregação sexual; as coberturas controladas; os partos por cesariana; a desmama forçada; a proximidade imposta com outros indivíduos; e a inevitável presença de humanos, cães e maquinaria ou equipamentos (Hafez e Hafez, 2004).

O fato é que os animais domésticos mudaram rapidamente o seu comportamento em curto tempo evolutivo. Beilharz (1985) relatou que o comportamento inato é capaz de mudar através das gerações e sofrer modificações ambientais.

Esta mudança de comportamento dos animais domésticos é devido à crescente escolha dos reprodutores que é praticada de acordo com o manejo das propriedades, com isso não permitindo que os animais escolham o seu parceiro sexual e possam ter um namoro mais prolongado (Beilharz, 1985). Os animais domésticos são mais precoces do que os selvagens (Mignon-Grasteau et al., 2005). Assim, os animais domésticos respondem espontaneamente à necessidade de se acasalar rapidamente com o companheiro escolhido pelo homem e frequentemente reproduzem em uma estação favorável de produção de alimentos (Beilharz, 1985).

Na família Bovidae, um dos fatores que determinou a domesticação foi o fato deles serem poligâmicos. A poligamia foi uma característica favorável à domesticação por causa de poucos machos poderem emprenhar muitas fêmeas (Murphey e Ruiz-Miranda, 1998; Hafez e Hafez, 2004).

Em relação ao comportamento sexual em búfalas não foram observadas diferenças no comportamento sexual das búfalas selvagens e as domesticadas (Baruselli, 1992; Tulloch, 1992)

De acordo com Setchell (1992) os animais selvagens apresentam uma atividade reprodutiva estacional, condicionada pela necessidade de coincidir o 
OLIVEIRA, A.F.M. et al. O processo de domesticação no comportamento dos animais de produção. PUBVET, Londrina, V. 5, N. 31, Ed. 178, Art. 1204, 2011.

parto e a desmama com uma estação climática que satisfaça as exigências de temperatura e alimento da prole. Esta característica se perde durante o processo de domesticação, mas ainda encontra-se presente em algumas espécies (Bastianetto et al., 2005). As ovelhas domésticas são menos sazonais que as ovelhas selvagens, mas a maioria das raças domésticas ainda retém um padrão sazonal significativo (Setchell, 1992). Por outro lado, os búfalos apresentam estacionalidade reprodutiva mesmo quando estão em locais com boa disponibilidade de alimento durante todo o ano. A manifestação da estacionalidade reprodutiva nos búfalos é influenciada pelo aumento da distância da linha do Equador (Zicarelli, 1997).

Em bovinos, não há nenhum efeito sazonal nos animais domesticados, mas sabe-se que os selvagens eram sazonais. Na Europa, porcos selvagens têm um padrão sazonal de reprodução, em contraste à maioria dos porcos domésticados (Setchell, 1992).

O comportamento reprodutivo é o que mais evidencia as mudanças ocorridas no processo de domesticação dos animais em relação aos seus antepassados selvagens. Essas mudanças podem ser explicadas pelas diversas biotécnicas reprodutivas que estão sendo utilizadas em animais de produção.

A Figura 7 apresenta um resumo do comportamento reprodutivo na domesticação.

\section{> Ocorreu degeneração do comportamento}

- Perderam os rituais de comportamento

- Perderam a opção de escolha de companheiros

- Diminuíram o comportamento de corte

$>$ Exemplos:

- Bovinos: poligâmicos

- Bubalinos: mesmas características nos selvagens e nos domesticados

- Ovinos: menor sazonalidade

Figura 7 - Comportamento reprodutivo na domesticação 
OLIVEIRA, A.F.M. et al. O processo de domesticação no comportamento dos animais de produção. PUBVET, Londrina, V. 5, N. 31, Ed. 178, Art. 1204, 2011.

\section{Comportamento materno na domesticação}

Em animais selvagens o comportamento materno é essencial à sobrevivência dos filhotes e nos animais domesticados este comportamento não é tão essencial. Isto pode ser devido a que algumas práticas-padrão interferem nas ligações maternas entre fêmeas e filhotes como, por exemplo, a separação precoce do recém-nascido de sua mãe, como ocorre em gado leiteiro ou na produção de leitões, que induz à modificação do comportamento dos animais jovens (Mignon-Grasteau et al., 2005). De acordo com os mesmos autores, na maioria das espécies de bovídeos selvagens as fêmeas parturientes deixam o rebanho e se isolam durante a parição e o período pós-natal imediato. A maior parte dos procedimentos de manejo após a domesticação impede a realização desses comportamentos e com isso aumenta as chances de interferência de outros membros do rebanho.

Em ovelhas a domesticação diminuiu: a- o isolamento dos animais durante a parição; b- as lambidas imediatas nos cordeiros recém-nascidos; ca defesa dos cordeiros dos predadores; e d- teor de lipídio mais no colostro do que nas ovelhas selvagens segundo Dwyer e Lawrence (2005). Por outra parte, Dwyer et al. (1998) relataram que as ovelhas de uma linhagem pouco selecionada vocalizam mais em resposta ao afastamento de seus filhotes do que as ovelhas de uma linhagem altamente selecionada. Entretanto, os cordeiros de linhagem mais selecionada apresentaram maior taxa de vocalização em resposta à separação de suas mães do que os cordeiros de linhagens menos selecionados. Outro padrão diferencial é que os cordeiros domesticados são mais lentos em ficar de pé e dar a primeira mamada e de reconhecer a mãe do que os selvagens (Dwyer e Lawrence, 2005).

O processo de domesticação dos suínos foi baseado na seleção pelo crescimento rápido, pela qualidade e quantidade de carne, pelo número de leitões desmamados por ano, mas teve pouca influencia em relação à habilidade materna. Gustafsson et al. (1999) estudaram o comportamento materno das porcas, avaliaram a construção de ninho comparando porcas 
OLIVEIRA, A.F.M. et al. O processo de domesticação no comportamento dos animais de produção. PUBVET, Londrina, V. 5, N. 31, Ed. 178, Art. 1204, 2011.

domésticas e selvagens, estes autores não encontram diferença entre a frequência ou padrão do comportamento na construção do ninho entre os animais selvagens e os domesticados. Contudo, as porcas domésticas permitiram que os leitões massageassem o úbere durante um tempo mais longo depois da expulsão do leite do que as porcas selvagens.

Gustafsson et al. (1999) e Spinka et al. (2000) concluíram que existem grandes semelhanças no comportamento materno das porcas selvagens e das porcas domésticas. Essas semelhanças poderiam indicar que as porcas selvagens adaptaram-se à proteção humana e que a habilidade materna em porcas não foi modificada substancialmente pela domesticação.

Na Figura 8 apresenta-se um resumo do comportamento materno após a domesticação.

\section{Comportamento materno de animais domesticados: \\ > Não ocorre o isolamento das fêmeas durante a parição e pós-parto \\ $>$ Aumenta a vocalização dos filhotes \\ > Os filhotes demoram mais em ficar de pé e dar a primeira mamada \\ $>$ A habilidade materna não foi alterada}

Figura 8 - Comportamento materno após a domesticação

\section{Comportamento alimentar na domesticação}

$\mathrm{Na}$ natureza, os animais gastam uma grande parte do seu tempo e energia na procura de comida e água. Assim, o comportamento alimentação apresenta um alto custo energético, induzindo a estratégias que são otimizadas nas condições selvagens, como a busca por alimento.

Nos animais domésticos estes custos foram reduzidos (Gustafsson et al., 1999; Andersen et al., 2006). A maioria dos animais em cativeiro é dependente do homem para providenciar a sua dieta apropriada, que é frequentemente uniforme e sazonal. Em cativeiro, a comida e a água são providas frequentemente em um único local e em suficientes quantidades de 
OLIVEIRA, A.F.M. et al. O processo de domesticação no comportamento dos animais de produção. PUBVET, Londrina, V. 5, N. 31, Ed. 178, Art. 1204, 2011.

forma que o tempo e energia gastos para alimentar o animal, são aparentemente muito reduzidos, quando comparados ao dos animais selvagens (Newberry, 1995; Mignon- Grasteau et al., 2005).

Gustafsson et al. (1999) estudaram porcos híbridos de animais selvagens (Holland Landracc $x$ Wild boar) e porcos domésticos (Sus scrofa), identificando que os porcos híbridos tenderam a usar uma estratégia de forragear mais exigente que a dos porcos domésticos. Portanto, os porcos selvagens gastaram mais energia quando comparados aos porcos domésticos.

Na Figura 9 apresentam-se as características da alimentação dos animais domesticados.

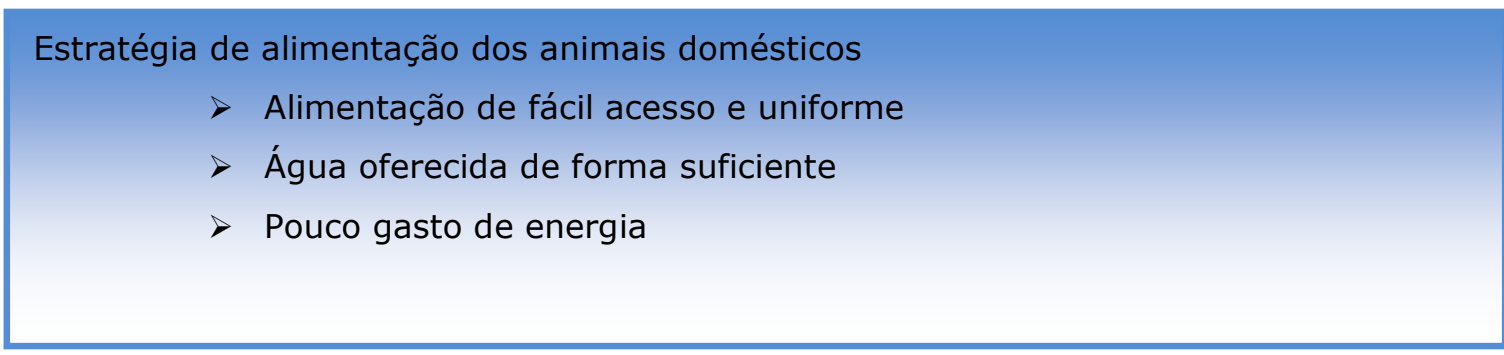

Figura 9 - Comportamento alimentar dos animais domesticados

\section{Comportamento social na domesticação}

A maioria das espécies domesticadas é constituída de animais naturalmente sociais que vivem em grupos grandes, altamente organizados com uma hierarquia social estável. Pode-se observar esta hierarquia nas cabras (Barroso et al., 2000) nos búfalos (Tulloch, 1992) e nos bovinos (Lazo, 1994)

As cabras selvagens possuem uma complexa e forte hierarquia linear e vivem em grupos sociais grandes (Barroso et al., 2000).

Os Búfalos Africanos, Syncerus caffer (Sinclair, 1977 citado por LAZO 1994) apresentam grupos sociais que são altamente estáveis, isto provavelmente aumentaria os benefícios entre os indivíduos como à eficiência alimentar e nos processos biológicos como a reprodução. 
OLIVEIRA, A.F.M. et al. O processo de domesticação no comportamento dos animais de produção. PUBVET, Londrina, V. 5, N. 31, Ed. 178, Art. 1204, 2011.

Nos bovinos há uma organização hierárquica, observando-se que os jovens machos são menos aderentes aos grupos femininos e as fêmeas permanecem mais perto das mães, concluindo uma relação matriarcal com afinidades específicas entre as fêmeas (Lazo, 1994). Para os animais domésticos, a estrutura do grupo social frequentemente inclui animais do mesmo sexo ou idade.

A característica de organização dos animais em grupos sociais foi um atributo que favoreceu a domesticação, entretanto, resultou na interferência das relações sociais com o homem que controla a reprodução e a produção (Mignon-Grasteau et al., 2005).

Os resultados destas interferências podem ser relatados no processo de seleção para aumentar crescimento de animais afetando comportamento social. Este processo de seleção pode aumentar ou diminuir a agressão (Brannas et. al., 2005).

Em ovelhas e cabras domésticas, observou-se uma diminuição da resposta ao predador (ex. a distância de fuga mais curta, tempo de reação mais lento) do que as ovelhas e as cabras selvagens (Hansen et al., 2001; Hemmer, 1990).

Observa-se na Figura 10 as estratégias do comportamento social dos animais domésticos. 
OLIVEIRA, A.F.M. et al. O processo de domesticação no comportamento dos animais de produção. PUBVET, Londrina, V. 5, N. 31, Ed. 178, Art. 1204, 2011.

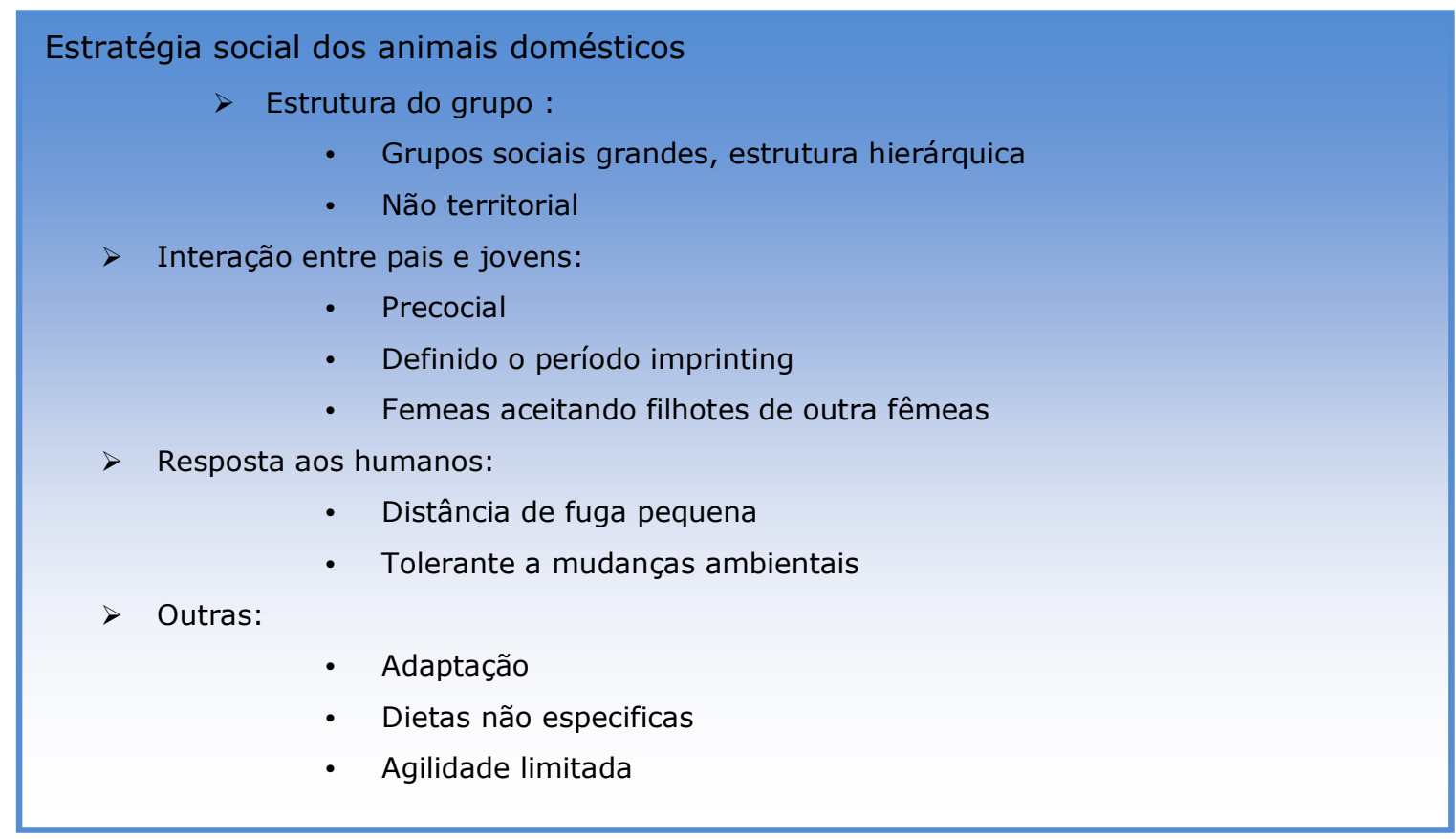

Figura 10 - Comportamento social dos animais domésticos.

Em conclusão, o grau de pré-adaptação de uma espécie para domesticação é dependente da capacidade social da espécie em adaptar-se aos processos desenvolvimento e evolutivos a uma variedade de ambientes (Balon, 1995). Por outra parte, animais sociais são menos sensíveis ao estresse psicológico, eles aceitam domínio humano mais facilmente como parte de uma estrutura hierárquica natural.

\section{Considerações finais}

A domesticação é um processo evolutivo no qual, através dos anos, muitas características do comportamento mudaram de um animal selvagem para um animal doméstico.

Então, como escolhe uma espécie para domesticar?

A Figura 11 mostra os critérios pelos quais tem se escolhido uma espécie para domesticar. 
OLIVEIRA, A.F.M. et al. O processo de domesticação no comportamento dos animais de produção. PUBVET, Londrina, V. 5, N. 31, Ed. 178, Art. 1204, 2011.

$$
\begin{aligned}
\text { Critérios: } & \\
& >\text { Animais que vivem em grupos sociais } \\
& >\text { Animais que apresentam hierarquia social } \\
& >\text { Animais que apresentam liderança } \\
& >\text { Machos ficam frequentemente separados do grupo das fêmeas } \\
& >\text { Apresentam pequena distância de fuga } \\
& >\text { Fácil adaptação ao ambiente } \\
& >\text { Apresentar dieta diversificada } \\
& >\text { Possuir baixa agilidade }
\end{aligned}
$$

Figura 11 - Critérios para selecionar animais para ser domesticados.

É muito difícil estudar as mudanças comportamentais das espécies no processo de domesticação, seria necessário fazer comparações de populações selvagens e domésticas. Hoje em dia muitas dessas populações selvagens já não existem ou estão em extinção.

\section{Referencias bibliográficas}

ANDERSEN, I. L., NAEVDAL, E., BØE, E. K., BAKKEN, M., The significance of theories in behavioural ecology for solving problems in applied ethology - possibilities and limitations. Applied Animal Behaviour Science, v.97, p. 85-104, 2006.

BARROSO, F. G., ALADOS, C. L., BOZA, J., Social hierarchy in the domestic goat: effect on food habits and production. Applied Animal Behaviour Science, v. 69, p.35-53, 2000.

BALON, E. K., Origin and domestication of the wild carp, Cyprinus carpio: from Roman gourmets to the swimming flowers. Aquaculture, v.129, p.3-48, 1995.

BARUSELLI, P. S. Atividade ovariana e comportamento reprodutivo no período pós-parto em búfalos (Bubalus bubalis). Dissertação (Mestrado em Reprodução Animal) São Paulo, Faculdade de Medicina Veterinária e Zootecnia, Universidade de São Paulo, 1992. 99p.

BASTIANETTO, E., ESCRIVÃO, S.C., OLIVEIRA, D.A.A., Influencia das características reprodutivas da búfala na produção, composição e qualidade do leite. Rev. Bras. Reprod. Anim. V. 1, p. 49-52, 2005.

BEILHARZ, R. G., Innate Behaviour. Ethology of farm animals. A comprehensive study of the behavioural features of the common farm animals. (ed) A. F. Fraser. Elsevier Science Publishers B.V. New York. P.83-90, 1985. 
BRÄNNÄS, E., CHAIX, T., NILSSON, J., ERIKSSON, L.O., Has a 4-generation selection programme affected the social behaviour and growth pattern of Arctic charr (Salvelinus alpinus)? Applied Animal Behaviour Science, v. 94, p. 165-178, 2005.

BRUFORD, M. W., BRADLEY, D. G., LUIKART, G., DNA markers reveal the complexity of livestock domestication. Nature Reviews Genetics, v.4, p. 900-910, 2003

DIAMOND, J. Evolution, consequences and future of plant and animal domestication. Nature, v. 418, p. $700-707,2002$.

DWYER, C., MCLEAN, K. A., DEANS, L.A., CHIRNSIDE, J., CALVERT, S. K., LAWRENCE, A. B., Vocalisations between mother and young in sheep: effects of breed and maternal experience. Applied Animal Behaviour Science, v. 58, p. 105-119, 1998.

DWYER, C., LAWRENCE, A. B., A review of the behavioural and physiological adaptations of hill and lowland breeds of sheep that favour lamb survival. Applied Animal Behaviour Science, v.92, p. 235-260, 2005.

FOX, M. W., The influence of domestication upon behaviour of animals. Abnormal behaviour in animals. (ed) Fox, M.W., W. B. Saunders Company. Toronto.P 64-76, 1968.

GILLESPIE, JAMES R. Modern Livestock \& Poultry Production, 6e. Albany, New York: Delmar, a division of Thomson Learning, Inc. 2002.

GUSTAFSSON, M., JENSEN, P., DE JONDE, F. H., SCHUURMAN, T. Domestication effects on foraging strategies in pigs (Sus scrofa). Applied. Animal . Behaviour. Science, v.62, p. 305$317,1999$.

HABER, A., DAYAN, T., Analyzing the process of domestication: hagoshrim as a case study. Journal of Archaeological Science, v. 31, p. 1587-1601, 2004.

HAFEZ, E.S.E., HAFEZ, B. Ciclos reprodutivos: Reprodução Animal. 7 ed. São Paulo: Manole, p. $55-67,2004$.

HANSEN, L., CHRISTIANSEN, F., HANSEN H. S., BRAASTAD, B. O., BAKKEN, M., Variation in behavioural responses of ewes towards predator-related stimuli. Applied Animal Behaviour Science, v. 70, p. 227-237, 2001.

HERMMER, H. Domestication - The Decline of Enviromental Appreciation. Cambridge Univ. Press, Cambridge, 1990.

JENSEN, P., Domestication- from behaviour to genes and back again. Applied Animal Behaviour Science, v.97, p.3-15, 2006.

KAMINSKI, J., RIEDEL, J., CALL, J., TOMASELLO, M., Domestic goats, Capra hircus, follow gaze direction and use social cues in an object choice task. Animal Behaviour, p.11-18, 2005.

LAZO, A. Social segregation and the maintenance of social stability in feral cattle population. Animal Behaviour, v.48, p. 1133-1141, 1994.

MIGNON- GRASTEAU, S., BOISSY, A., BOUIX, J., FAURE, J.M., FISHER, A.D., HINCH, G. N., LE NEINDRE, P., MORMĖDE, P., PRUNET, P., VANDEPUTTE, M., BEAUMONT, C., Genetics of 
adaptation and domestication in livestock. Livestock production Science, v. 93, p. 3-14, 2005.

MURPHEY, R. M., RUIZ-MIRANDA, C. R. Domesticated ruminant behavior. In: Greenberg, G., Haraway, M.M. (eds). Comparative Psychology: a handbook, p. 393-404, 1998.

PRICE, E. O., Behaviour aspects of animal domestication. Q. Rev. Biol. v.59, p.1-32, 1984.

PRICE, E. O., Behavioral development in animals undergoing domestication. Applied Animal Behaviour Science, v.65, p. 245-271, 1999.

SETCHELL, B. P., Domestication and reproduction. Animal Reproduction Science, v.28, p. 195-202, 1992.

SIMM, G.,CONINGTON J., BISHOP, S. C., DWYER, C. M., PATTINSON, S., Genetic selection for extensive conditions. Applied Animal Behaviour Science, v.49, p. 47-59,1996.

SPINKA, M.,ILLMANN, G., JONGE, F., ANDERSSON, M., SCHUURMAN, T., JENSEN, P. Dimensions of maternal behaviour characteristics in domestic and wild $\mathrm{x}$ domestic crossbred sows. Applied Animal Behaviour Science, v.70, p. 99-114, 2000.

TULLOCH, D. G. Behaviour of non-domesticated swamp buffaloes in Australia. In: Tulloch, N. M., Holmes, J. H. G. (ed) Buffalo Production. Australia: Elsevier, p. 247-270, 1992.

ZICARELLI, L., Stagionalità reproduttiva nella buffalo. In: International Course of Biotechnology in Buffalo Reproduction, 3th, Napoli, Italia. Proceedings ... Napoli: Bubalus bubalis Suppl. p.29-52, 1997. 